\title{
Treatment of Psychosis and Dementia in Parkinson's Disease
}

\author{
Dr. Jennifer G. Goldman, MD, MS ${ }^{1}$ and Samantha Holden, MD $^{1}$ \\ ${ }^{1}$ Rush University, Department of Neurological Sciences, Chicago IL, USA
}

\section{Opinion Statement}

Parkinson's disease (PD) has been increasingly recognized as having a multitude of non-motor symptoms including psychosis, cognitive impairment and dementia, mood disturbances, fatigue, apathy, and sleep disorders. Psychosis and dementia, in particular, greatly affect quality of life for both patients and caregivers and are associated with poor outcomes. Safe and effective treatment options for psychosis and dementia in PD are much needed. Antipsychotics with dopamineblocking properties can worsen parkinsonian motor features and have been associated with increased morbidity and mortality in elderly, dementia patients. For treating PD psychosis, a first step would be eliminating confounding variables, such as delirium, infections or toxic-metabolic imbalances, followed by simplifying parkinsonian medications as tolerated. If additional treatment is warranted after such interventions, clozapine or quetiapine can be implemented at the low dose levels typically needed by PD patients. Although quetiapine is easy-to-use in clinical settings, does not require blood count monitoring like clozapine, and is anecdotally beneficial, it remains "investigational" in evidence-based medicine reviews. Though not currently available, the novel 5-HT2a inverse agonist, pimavanserin has shown promise in the treatment of PD psychosis. Current treatments for PD dementia are mostly derived from those utilized in Alzheimer's disease, focusing mainly on cholinesterase inhibitors and memantine, a NMDA receptor antagonist. Rivastigmine, the only approved medication for PD dementia, is a reasonable first choice. Other cholinesterase inhibitors and memantine have not yet achieved recommendation status in evidence-based medicine reviews but are well tolerated in studies of PD dementia patients. At present, there are no approved treatments for mild cognitive impairment in PD, but rasagiline, a selective MAO-B inhibitor, and atomoxetine, a serotonin norepinephrine reuptake inhibitor, have been recently studied. Non-pharmacological interventions, including cognitive therapy, physical activity, music and art therapy and non-invasive brain stimulation techniques, may be promising options for PD cognitive impairment but await rigorous study.

\footnotetext{
"Corresponding author: Dr. Jennifer G. Goldman, MD, MS, Contact details: Rush University Medical Center, Department of Neurological Sciences, Section of Parkinson Disease and Movement Disorders, 1725 W. Harrison Street, Suite 755, Chicago, IL 60612, Telephone: 312-563-2900; Fax: 312-563-2024; Jennifer_G_Goldman@ rush.edu.

Jennifer_G_Goldman@rush.edu; Samantha_Holden@ rush.edu

Compliance with Ethics Guidelines

Conflict of Interest

Samantha Holden declares that she has no conflict of interest.

Human and Animal Rights and Informed Consent

This article does not contain any studies with human or animal subjects performed by any of the authors.
} 


\section{Keywords}

Acetylcholine; Antipsychotics; Attention; Cholinesterase inhibitors; Clozapine; Cognitive deficits; Cognitive training; Dementia; Donepezil; Dopamine; Executive function; Hallucinations; Memantine; Memory; Mild cognitive impairment; Neuropsychiatric; Non-motor symptoms; Nonpharmacological treatments; Parkinson's disease; Psychosis; Quetiapine; Rivastigmine; Serotonin

\section{Introduction}

Parkinson's disease (PD) is increasingly recognized as a multifaceted disorder, with considerable non-motor symptoms emerging throughout the disease course. In a survey of 1,072 patients with PD, non-motor symptoms were nearly universally reported, with a mean number of 7.8 non-motor symptoms per patient [1]. Among the $98.6 \%$ of patients who reported non-motor symptoms, psychiatric symptoms were the most frequent, with $66.8 \%$ endorsing their presence. Non-motor symptoms in PD include dementia, psychosis, depression, anxiety, apathy, impulse control disorders, fatigue, and sleep disturbances, with PD becoming more accurately described as a neuropsychiatric disorder [2]. Of this group, psychosis and dementia frequently co-exist, and the development of one symptom often heralds the other. Psychosis and dementia are associated with poorer quality of life, increased morbidity and mortality, and increased caregiver burden and nursing home placement [3-5]. Therefore, safe and effective treatments for these neuropsychiatric symptoms are necessary to avoid such negative outcomes in the PD population.

\section{Psychosis in PD}

The lifetime prevalence of psychosis in PD is likely over $50 \%$ according to recent epidemiological studies [6], with a range of 25-60\% depending on diagnostic criteria used. The more recent National Institute of Neurological Disorders and Stroke and the National Institute of Mental Health (NINDS-NIMH) criteria for PD psychosis include milder psychotic phenomena, such as visual illusions or sense of presence and thus, have led to higher prevalence estimates [7]. In one study of 116 PD patients, the cross-sectional prevalence of PD psychosis was $43 \%$ with the more traditional definition of psychosis, namely the presence of hallucinations or delusions [8], but with the more inclusive NINDSNIMH criteria, increased to $60 \%$. These diagnostic criteria require the presence of at least one of the following: hallucinations, delusions, illusions, or false sense of presence. Psychosis must occur with in the setting of a clear sensorium and a chronic course ( $\geq$ one month), either recurrent or continuous. Other medical, neurologic or psychiatric causes for the symptoms must be excluded. Risk factors for PD psychosis include advancing age, longer PD duration, worse motor severity, presence of sleep disorders, depression and autonomic impairment, though the most significant risk factor remains the presence of dementia [9-11]. In PD patients with dementia, 70\% report visual hallucinations, compared to only $10 \%$ of patients without dementia [12].

The spectrum of psychotic symptoms in PD ranges widely, from mild visual illusions to fully formed, systemized hallucinations and delusions [6, 13]. Visual hallucinations are most common, occurring in up to one-third of PD patients on chronic dopaminergic therapy. 
These hallucinations may be non-threatening, brief, and well formed; reports of small children or animals are common. Hallucinations occur more frequently during times of decreased environmental stimulation, such as in the evening, low ambient lighting, or decreased sound levels. A false sense of presence or passage, as well as visual illusions, are considered minor psychotic phenomena and can affect anywhere from 17 to $72 \%$ of PD patients. While auditory, olfactory or tactile hallucinations are less common than their visual counterparts, they do occur; up to $20 \%$ of patients report auditory hallucinations. Non-visual hallucinations or mixed hallucinations are more common in patients who develop psychotic symptoms at advanced ages [13]. Hallucinations in PD differ from those found in schizophrenia and delirium, in that there is a predominant visual phenotype, retained insight, and underlying clear sensorium. However, with PD progression and increased cognitive deficits, hallucinations can worsen and insight can be lost, which may lead to worsened quality of life and increased caregiver burden. PD patients residing in nursing homes had a greater presence and severity of hallucinations, compared to community-dwellers; $82 \%$ of the PD patients in nursing homes reported hallucinations, while only $5 \%$ of those still living independently did [5].

Delusions in PD occur less frequently than hallucinations, with prevalence estimates ranging from $5-10 \%$ [6]. The delusions are usually paranoid or jealous in character and focus on a single theme, such as spousal infidelity or abandonment by family. Delusions of a phantom boarder, living in the patient's home, also have been reported in PD. Compared to primary psychiatric disorders, the delusions in PD are usually not grandiose, somatic or bizarre. Misidentification syndromes are also reported, including Capgras, Fregoli and Othello syndromes $[14,15]$.

Though once attributed primarily to dopaminergic medication side effects, PD psychosis is more likely related to a complicated interplay between intrinsic pathophysiological changes and extrinsic variables [16] (Table 1). Intrinsic processes include neurochemical changes affecting dopamine, serotonin and acetylcholine; aberrant cortical and brainstem activation patterns; sleep disturbances; primary visual impairment; and abnormal attentional, cognitive, and visuospatial functioning. Extrinsic factors include alterations in the visual environment and use of dopaminergic, anticholinergic, and central nervous system-acting medications. The underlying pathophysiology at the neurotransmitter level is related to complex interactions among dopamine, acetylcholine and serotonin. Overstimulation of dopaminergic receptors, particularly in the mesocorticolimbic region, may occur in the context of chronic dopaminergic therapy and enhanced sensitivity of native receptors, thereby implicating the kindling model [17]. Imbalances between dopamine and acetylcholine also play a role, with compensatory over-activity of acetylcholine in response to dopamine deprivation. Neurotransmitter imbalances abound, with dopaminergic medications also decreasing intrinsic serotonin levels. In autopsies of PD patients, there are abnormalities in 5HT-2A receptors with increased serotonin binding in the inferior temporal cortex in PD patients who had psychosis compared to those who did not [18] (Fig. 1). 


\section{Treating psychosis in PD}

When psychotic symptoms develop in a PD patient, the first step, especially when the onset is acute, is to rule out secondary causes, such as delirium, infection, or toxic-metabolic etiologies. Next, one should consider discontinuing any non-essential non-PD medications that could contribute to psychosis. These medications may include tricyclic antidepressants, anticholinergics, benzodiazepines, and opioids. After simplifying the non-PD medication regimen, the next step would be reducing or discontinuing PD medications. For example, one may first wean or stop monoamine oxidase B (MAO-B) inhibitors (e.g., selegiline, rasagiline), then amantadine, followed by dopamine agonists (e.g., pramipexole, ropinirole, rotigotine) and catechol-O-methyltransferase (COMT) inhibitors (e.g., entacapone, tolcapone), and lastly, reducing levodopa doses [19]. Adjusting PD medication regimens can be a delicate balancing act; as the psychotic symptoms may improve, motor symptoms can worsen. If simplification of the PD drug regimen does not produce satisfactory improvement in psychotic symptoms, one must consider adding an antipsychotic medication. Treatment of PD psychosis is a particular challenge, as typical and several atypical antipsychotic medications block dopamine (D2) receptors and can worsen motor symptoms. In addition, antipsychotics carry a black box warning from the Food and Drug Administration (FDA) for use in elderly patients, especially those with underlying dementia, due to increased risk of mortality and cerebrovascular events. Another potential complication of the use of antipsychotic medications in the advanced PD population and a related condition, dementia with Lewy bodies, is neuroleptic sensitivity; this can occurs in up to $40 \%$ of PD patients exposed to these medications [20]. Neuroleptic sensitivity is a severe psychomotor adverse reaction, which can resemble neuroleptic malignant syndrome. While this adverse event can occur with either typical or atypical antipsychotics, it is more common with the firstgeneration medications such as haloperidol. In general, typical antipsychotics and those atypical antipsychotics with greater D2 blockade should be avoided in the parkinsonian population, given the potential for worsened motor symptoms. Therefore, choosing a safe and effective antipsychotic medication to treat PD patients can be challenging. Other common side effects of atypical antipsychotic medications that require monitoring in PD patients are sedation and orthostasis. Antipsychotic medications with greater serotonergic profiles are preferred in parkinsonian patients since they are less likely to worsen motor symptoms. To date, there is no FDA approved medication for PD psychosis, and all current treatments are used "off-label." The most frequently used medications for the treatment of PD psychosis include clozapine and quetiapine.

Clozapine is the current "gold standard" treatment for PD psychosis, with efficacy in treating psychosis without worsening motor symptoms demonstrated in randomized clinical trials (Level B evidence) [21, 22]. By selectively binding D1 mesolimbic receptors, clozapine spares the striatal dopamine $\mathrm{D} 2$ receptors, which along with its greater serotonergic 5HT-2A/2C affinity, leads to its favorable motor profile in PD. It is the only antipsychotic medication that has consistently been found to be efficacious in PD psychosis randomized controlled trials [23-25] and has an acceptable safety risk with specialized monitoring [22]. Clozapine carries a $0.38 \%$ risk of agranulocytosis, which, while small and idiosyncratic, can be exceedingly dangerous. Therefore, safety monitoring includes weekly 
complete blood counts for the first six months, followed by every other week for the next six months, and then monthly for the duration of treatment. Doses used in PD psychosis trials and clinical practice range from 6.25 to $50 \mathrm{mg}$ per day. These doses are much lower compared to doses of 300 to $900 \mathrm{mg}$ per day used in schizophrenia. A starting dose of 6.25 $\mathrm{mg}$ given nightly is recommended in $\mathrm{PD}$, increasing by the same amount every four to seven days until symptoms improve or side effects emerge. One should be mindful of other clozapine-related side effects such as sedation, orthostatic hypotension or lightheadedness, and increased drooling, which can occur in PD in general.

Quetiapine, an atypical dibenzothiazepine which is structurally similar to clozapine, is also frequently used for the treatment of PD psychosis, despite less consistently supportive data from double-blind, placebo-controlled, randomized trials than clozapine [21, 22]. Similar to clozapine, quetiapine has greater serotonergic affinity to 5HT2 receptors than to D2 receptors, which confers a more favorable motor profile in $\mathrm{PD}$. Recent clinical trials provide conflicting data of its efficacy in treating PD psychosis as measured by psychosis rating scales [26-29]. Thus, there is insufficient evidence for its use in PD psychosis. Quetiapine, however, did not significantly worsen motor function in the clinical trials. Thus, quetiapine has been regarded as having Level C evidence [21] or having "insufficient evidence, acceptable safety risk without need for specialized monitoring, but investigational practice implications" [22]. However, quetiapine is appealing in clinical settings due to its ease of use and lack of blood count monitoring. In clinical practice, quetiapine was prescribed in about 2/3rds of patients in an outpatient United States Veterans Affairs population, with few treated with clozapine [30]. Again, relatively low doses of quetiapine are needed to treat PD psychosis. In studies and clinical practice, quetiapine is generally well-tolerated and dosed starting at $12.5 \mathrm{mg}$ nightly and increasing by the same amount every four to seven days until reaching a goal dose of 50-150 mg nightly. Side effects include sedation and orthostatic hypotension.

Recent studies suggest that pimavanserin may hold promise as another treatment option for PD psychosis. Pimavanserin is a unique medication that acts as an inverse agonist of the 5HT2a receptors. This mechanism of action is encouraging for use in PD patients, as it avoids dopamine blockade. In animal studies, pimavanserin has an exceedingly high therapeutic ratio, with reduction of psychotic symptoms at doses more than hundred times smaller than those that induced motor side effects [31]. In its first phase III randomized controlled trial, there was no significant improvement in psychotic symptoms compared to placebo, though post-hoc analysis showed statistically significant changes at doses of $40 \mathrm{mg}$ per day at two weeks after treatment initiation [32]. The subsequent trial demonstrated efficacy of pimavanserin $40 \mathrm{mg}$ daily, meeting the primary endpoint of improvement in the Scale for Assessment of Positive Symptoms, as well as secondary endpoints of improvement in caregiver burden, daytime somnolence and sleep quality [33]. There were no motor side effects, and the medication was well tolerated with a safety profile similar to placebo. Based on these trials, the FDA has invited the developer to file for approval of pimavanserin for the treatment of PD psychosis [34].

Cholinesterase inhibitors such as rivastigmine and donepezil have been considered in the treatment of chronic, mild to moderate psychotic symptoms in PD. However, large, double- 
blind, placebo-controlled studies with PD psychosis as the primary outcome have not been performed. Several smaller studies, case series, or open label trials have examined cholinesterase inhibitors in the treatment of hallucinations and delusions in PD [35-39]. In other studies, however, these medications have been investigated in the context of treating PD dementia and cognitive impairment [40-42]. Rivastigmine has been more consistently efficacious in psychosis [38-41], compared to donepezil [35-37, 42, 43]. Subgroup analyses of the large double-blind, placebo-controlled trial of rivastigmine in PD dementia revealed that rivastigmine was mildly more effective in improving PD cognitive scores in hallucinators but did reduce the hallucinations per se [40, 44].

Most other members of the antipsychotic class should be avoided in the treatment of PD psychosis due to dopamine blockade. This includes both typical and atypical antipsychotics, including olanzapine and aripiprazole. Olanzapine has an unacceptable risk of motor side effects [45-47], and trials with olanzapine led to a black box warning due to its lack of efficacy and significant effect on worsening motor function. Aripiprazole, a partial dopamine agonist/antagonist, initially was thought be a candidate for treating PD psychosis but can worsen parkinsonism [48, 49].

\section{Dementia and cognitive impairment in PD}

In addition to psychosis, the spectrum of neuropsychiatric features in PD includes dementia and mild cognitive impairment. Cognitive impairment is a frequent complication of PD, with dementia occurring in about $80 \%$ after long-term follow-up [50, 51]. The incidence rate of dementia in PD is four to six times that of control populations, with about $10 \%$ of the PD population developing dementia per year [52]. Mild cognitive impairment (MCI) has become increasingly recognized in PD as a state in which cognitive deficits occur but are neither as severe nor as of impairing daily functions as in dementia. MCI occurs in about 20-50\% in PD patients and is recognized as a risk factor for the later development of PD dementia [53]. Cognitive deficits, including MCI, can occur early in PD and prior to treatment [54], and thus, no longer represent just a late stage phenomenon. In addition to MCI, other risk factors for PD dementia include advanced age, older age at disease onset and more severe motor deficits, particularly rigidity, postural instability and gait disturbance [52]. As discussed above, psychosis and dementia are risk factors for each other [9, 55-57]. Diagnostic criteria for PD dementia by a Movement Disorder Society (MDS) task force along with operational guidelines, require cognitive impairment in more than one cognitive domain (attention, executive function, visuospatial function, memory, and language) that is severe enough to impact daily living [52, 58]. More recently, diagnostic criteria for PD-MCI have been proposed by a MDS task force [59]. To date, the MDS PD dementia criteria have not been used in published clinical trials of agents for PD dementia, and use of the MDS PD-MCI criteria in clinical trials is emerging.

The most common cognitive problems in PD dementia include impaired attention and concentration, poor executive function and planning, difficulty with multi-tasking or initiating activity, short-term memory impairment and poor visuospatial function [52]. Similar cognitive domains affecting attention/working memory, executive function, memory, and visuospatial function can be impaired in PD-MCI [53, 60]. The underlying 
pathophysiology of PD cognitive impairment overlaps with cholinergic deficiency, bearing some similarity to Alzheimer's disease (AD) and provide a rationale for treatment with cholinesterase inhibitors. However, abnormalities in other neurotransmitters such as dopamine, serotonin, and norepinephrine contribute to PD cognitive dysfunction. Moreover, the underlying pathologies of PD dementia are heterogeneous [61, 62]. The relationship between PD dementia and dementia with Lewy bodies (DLB) is also interesting, as one of the determinants in the criteria refers to the timing of onset of dementia relative to parkinsonism [63]; for PD dementia, motor symptoms must be present for one year prior to the onset of dementia. The question remains if whether these two diseases are discrete entities or rather variations within an overarching spectrum of disease [64].

\section{Treating dementia and cognitive impairment in PD}

Treatment of PD dementia is largely based on the cholinergic hypothesis. Unfortunately, the overall benefits of the currently available cholinesterase medications in PD dementia are modest in most treatment trials [21,22]. Cholinestesterase inhibitors are considered first-line treatment for PD dementia, as they are for AD. While most randomized controlled trials have shown limited improvements on objective outcomes (e.g., AD Assessment Scalecognitive battery, clinician's impressions, or selected neuropsychological tests), there has been evidence for improvement in more subjective areas, such as sociability, apathy and motivation, and behavioral disturbances [65]. Cholinesterase inhibitors are also considered safe and well tolerated, without the need for specialized monitoring. It is advised to check blood pressure and cardiac parameters (pulse, electrocardiogram) at time of treatment initiation since the parasympathomimetic effects of these medications can lead to bradycardia and syncope. Rivastigmine is the only FDA approved medication for the treatment of mild to moderate PD dementia. It inhibits both butyrylcholinesterase and acetylcholinesterase, unlike donepezil, which selectively inhibits acetylcholinesterase, and is available in two formulations (oral pills or a transdermal patch). There is a lower risk of gastrointestinal side effects, including nausea, vomiting and weight loss, with the transdermal patch as compared to oral dosing. Rivastigmine is probably efficacious in treating PD dementia, though the magnitude of benefit is modest (Level B evidence) [22, 44]. In addition, tremor can be exacerbated in up to $10 \%$ of PD dementia patients on rivastigmine. Starting doses of rivastigmine are $1.5 \mathrm{mg}$ twice daily for the oral formulation, increasing to a total of $6 \mathrm{mg}$ twice daily. The transdermal formulation starts at $4.6 \mathrm{mg}$ daily for the first four weeks, then increasing to $9.5 \mathrm{mg}$ daily as tolerated. Donepezil has also been found to be probably effective, but again the overall benefits are modest and the evidence is considered insufficient for its use in PD dementia [21, 22]. There have been several randomized controlled trials with donepezil in PD dementia, mostly small trials but one large study, but these reveal conflicting results for effectiveness [42, 43, 66, 67]. Dosing for donepezil starts at $5 \mathrm{mg}$ nightly, increasing to $10 \mathrm{mg}$ nightly after 6 weeks. Higher doses of the rivastigmine patch (13.3 mg/24 hours) and donepezil $23 \mathrm{mg} / \mathrm{day}$, which have been studied in $\mathrm{AD}$, have not been investigated in PD. Galantamine, another cholinesterase inhibitor, is also considered to have insufficient evidence for its use due to available trial data $[68,69]$. Galantamine is dosed at $4 \mathrm{mg}$ twice daily initially, titrating up to a goal of 12 mg twice daily. 
Memantine, an NMDA receptor antagonist, has been investigated in several randomized controlled trials in PD dementia and also DLB [70-72]. Results, however, have been conflicting regarding its efficacy. Some studies demonstrated improved clinical global impressions and speed on attention tasks [70] but others reveal no significant change on cognitive scores [72]. While there is insufficient evidence for its efficacy in PD dementia, it is considered safe and does not require specialized monitoring [22]. Memantine can be initiated at a dose of $5 \mathrm{mg}$ daily, titrating up to a goal dose of $10 \mathrm{mg}$ twice daily as tolerated. The extended release versions and doses up to $28 \mathrm{mg} /$ day have not been studied in PD.

Treatment intervention studies for mild cognitive deficits, or PD-MCI, are now expanding. At present, the emphasis has been on symptomatic improvement, though there may also be a role for disease-modifying strategies to prevent cognitive decline or dementia. The few studies with cholinesterase inhibitors for cognitive deficits in non-demented PD patients, one open label study of donepezil for executive dysfunction [73] and a double-blind, placebo-controlled study with galantamine [74], have yielded mixed results. Other studies of cholinesterase inhibitors in PD-MCI are currently underway (www.clinicaltrials.gov).

Non-cholinergic medications may be attractive treatment options for mild cognitive deficits in PD. Rasagiline, a selective, irreversible inhibitor of MAO-B which is also used for treating PD motor symptoms, has received attention in PD-MCI trials [75] (www.clinicaltrials.gov). A recent double-blind, placebo-controlled study of rasagiline 1 $\mathrm{mg}$ /day in PD patients with cognitive impairment, but not yet fulfilling criteria for dementia, demonstrated significant improvement in the attention domain with rasagiline, compared to placebo. There was no significant benefit seen in the cognitive domains of executive function, memory, visuospatial function or language. Few adverse events were reported, and no patients discontinued due to adverse events.

Another novel approach to treating cognitive impairment in non-demented PD focuses on the serotonin and norepinephrine systems. These systems are implicated in arousal, wakefulness, and mood. Increasing synaptic concentrations of serotonin can increase dopamine levels, as well as facilitate cholinergic transmission [76]. Atomoxetine, a serotonin norepinephrine reuptake inhibitor initially approved for treatment of attention deficit-hyperactivity disorder, is hypothesized to enhance the function of the locus ceruleus, a major norepinephrine source and promoter of wakefulness. Increased activation of this structure could have stimulant-like effects, thereby, improving attention and cognitive performance. Autopsy studies have shown that there is neuronal loss in the locus ceruleus in the brains of patients with PD dementia [77]. A pilot study of atomoxetine in non-demented PD patients with executive dysfunction reported clinically significant improvements in $75 \%$ of subjects on doses of 25 to $100 \mathrm{mg}$ daily [78]. Another treatment trial evaluating atomoxetine for depression in PD found that while the medication was not effective for mood symptoms, there were significant improvements in global cognition, as measured by the Mini-Mental State Exam [79]. Side effects in atomoxetine trials included insomnia, constipation, confusion, and hypomania.

There is growing interest in non-pharmacological treatments for cognitive impairment in PD [80]. Non-medication based treatments for PD dementia and PD-MCI include cognitive 
training, physical exercise and physical therapy, music and art therapy, and non-invasive brain stimulation techniques. One theory behind the use of cognitive therapy is the promotion of cognitive reserve in order to prevent or delay onset of cognitive impairment, as well as to slow progression once impairment is already present. Cognitive stimulation therapy is often group-based and consists of structured interventions with trained providers to improve cognitive performance. Cognitive rehabilitation can also be individualized, with therapists assisting patients in developing adaptive methods to address their cognitive deficits. Such strategies can include memory prompts, attentional cues and frequent reorientation. While there is Level B evidence for the use of these methods in AD [81], only a few studies in PD have been conducted. These studies vary in their design and methodologies (e.g., open label pilot studies; small, randomized controlled trials; different tasks; some computerized) and different cognitive targets (e.g., executive function, attention, and visuospatial abilities) [82-88] and have yielded mixed results. A recent randomized controlled trial on cognitive speed of processing training in PD patients using a commercially-available, self-administered computer program found that although speed of processing training improved a measure visual attention and visuospatial processing, there was improvement in the control group as well [89]. More research into this area is needed.

Physical activity and exercise have merit for improving motor symptoms in PD [90, 91], but supportive evidence for cognitive improvement is presently lacking. It is also theorized that the effects of combined physical activity and cognitive training therapies may be additive [92]. Music and art therapies have been shown to improve emotional well-being, quality of life, and motor function in PD [93], though specific evidence for its usefulness for cognitive impairment is sparse. Such creative therapies have been hypothesized to stimulate production of dopamine and serotonin. Physical intervention and exercise studies in PD have examined the effects of passive cycling, aerobic group exercise, and combined aerobic and resistance exercises on executive function and attention tests. However, few controlled studies have been conducted, and there are a number of study design concerns to consider [94-96]. Results suggest positive effects on cognitive measures in some studies, but further study is needed.

Non-invasive brain stimulation techniques, including repetitive transcranial magnetic stimulation (rTMS) and transcranial direct current stimulation (tDCS), are emerging treatment options for other neuropsychiatric conditions (e.g., mood disorders, migraines, stroke, and PD). While experimental, several studies have shown short-term improvements in cognitive function in AD patients when used alone [97] or in combination with cognitive stimulation therapy [98]. Several studies have examined rTMS and tDCS in PD cognitive impairment, though there is insufficient evidence to support its use at this point, and additional study is needed $[99,100]$.

\section{Treatments}

- Pharmacologic treatments

Atypical Antipsychotics

\section{$\underline{\text { Clozapine }}$}


- Standard dosage: Typically 6.25-50 mg/day for PD psychosis

- Contraindications:

Black-box
warning:
Elderly
patients
with
dementia-
related
psychosis
treated with
antipsychot
ics are at an
increased
risk of
death
compared
to placebo.
Absolute
neutrophil
count must
be $\geq$
2000/mm
and white
blood cell
count $\geq$
3500/mm
to begin
treatment.
Caution
with use in
patients
with
cardiovascu
lar disease,
especially
bradycardia
, syncope
or
orthostasis
Caution if
history of


seizures or

concurrent

medication

$\mathrm{s}$ that can

lower the

seizure

threshold.

- Main drug interactions:

Avoid
combinatio
n with
other QTc-
prolonging
agents,
anticholiner
gics, and
other
central
nervous
system
(CNS)
depressants
including
opioids and
benzodiaze
pines.
Avoid use
with
carbamazep
ine, which
may
enhance the
myelosuppr
essive
effect of
clozapine.
Cimetidine,
ciprofloxac
in, and
selective
serotonin
reuptake
inhibitors


(SSRIs)

may

increase

serum

concentrati

ons of

clozapine.

- Main side effects: Significant risk of potentially life-threatening agraunylocytosis (0.38\% risk).

Tachycardia (25\%), drowsiness (39-46\%), dizziness (19-27\%), insomnia (2-20\%), sialorrhea (31-48\%), weight gain (4-31\%), constipation (14-25\%).

- Special points: Clozapine is only available through a restricted program requiring enrollment of prescribers, patients and pharmacies to the Clozapine Registry.

- Cost/cost effectiveness: About \$130 for $25 \mathrm{mg}$ (100 tablets), $\$ 150$ for 50 mg (100 tablets)

\section{Quetiapine}

- $\quad$ Standard dosage: Typically 12.5-150 $\mathrm{mg} /$ day for PD psychosis

- Contraindications:

Black-box
warning:
Elderly
patients
with
dementia-
related
psychosis
treated with
antipsychot
ics are at an
increased
risk of
death


compared

to placebo.

Also use
with
caution in
patients
with
history of
seizures,
hepatic
impairment
, and
cardiovascu
lar disease.

- Main drug interactions: Avoid combination with other QTcprolonging agents, anticholinergics (quetiapine can enhance anticholinergic effects), and other CNS depressants including opioids and benzodiazepines.

- Main side effects: Somnolence (18-57\%), headache (7-21\%), dizziness (1-18\%), extrapyramidal symptoms (1-13\%), increased cholesterol (7-18\%), hyperglycemia (2-12\%), xerostomia (9-44\%), weight gain (3-23\%), increased appetite (2-12\%), constipation (6-11\%)

- Special points:

- Cost/cost effectiveness: About \$65 for $25 \mathrm{mg}$ (30 tablets), $\$ 100$ for 100 $\mathrm{mg}$ (30 tablets)

O Cholinesterase Inhibitors

$\underline{\text { Rivastigmine }}$

- Standard dosage: $1.50-6 \mathrm{mg}$ orally twice daily or 4.6-9.5 mg transdermally daily for PD dementia

- Contraindications: Use with caution in patients with history of seizures, 
COPD or asthma, and peptic ulcer disease (may increase gastric acid secretion).

- Main drug interactions: May exaggerate neuromuscular blockage effects of depolarizing neuromuscular-blocking agents, such as succinylcholine. May also enhance the bradycardic effect of beta-blockers.

- Main side effects: Dizziness (1-21\%), headache (3-17\%), nausea (5-47\%), anorexia (3-17\%), tremor/ parkinsonism (2-3\%), application site reactions for transdermal form $(<1-6 \%)$

- Cost/cost effectiveness: About \$240 for $1.5 \mathrm{mg}$ (60 tablets) and $\$ 224$ for $4.6 \mathrm{mg}$ (30 patches)

$\underline{\text { Donepezil }}$

- Standard dosage: 5-10 mg daily

- Contraindications: Use in caution in patients with history of sick-sinus syndrome, bradycardia or conduction abnormalities, syncopal episodes have been reported with donepezil. Cholinesterase inhibitors may have vagotonic effects.

- Main drug interactions: May exaggerate neuromuscular blockage effects of depolarizing neuromuscular-blocking agents, such as succinylcholine. May also enhance the bradycardic effect of beta-blockers.

- Main side effects: Insomnia (2-14\%), nausea (3-19\%), diarrhea (5-15\%)

- Special points: Patients weighing less than $55 \mathrm{~kg}$ may experience more GI side effects. If patients have 
insomnia, consider administration in the morning.

- Cost/cost effectiveness: About \$210 for $5 \mathrm{mg}$ or $10 \mathrm{mg}$ (30 tablets)

$\underline{\text { Galantamine }}$

- Standard dosage: 4-24 mg/day

- Contraindications: Use in caution in patients with history of sick-sinus syndrome, bradycardia or conduction abnormalities. Cholinesterase inhibitors may have vagotonic effects.

- Main drug interactions: May exaggerate neuromuscular blockage effects of depolarizing neuromuscular-blocking agents, such as succinylcholine. May also enhance the bradycardic effect of beta-blockers.

- Main side effects: Nausea (13-24\%), vomiting (6-13\%), diarrhea (6-12\%)

- Special points: Available as immediate release and extended release tablets, as well as a solution

- Cost/cost effectiveness: About $\$ 190$ for $4 \mathrm{mg}, 8 \mathrm{mg}$ or $12 \mathrm{mg}$ (60 tablets), $\$ 190$ for $8 \mathrm{mg}, 16 \mathrm{mg}$ or $24 \mathrm{mg}$ extended release, $\$ 270$ for $4 \mathrm{mg} / \mathrm{ml}$ solution $(100 \mathrm{~mL})$

O NMDA Antagonists

Memantine

- Standard dosage: 5-20 mg/day

- Contraindications: Use with caution in patients with cardiovascular disease, there was an increased incidence of cardiac failure, bradycardia and hypertension (compared with placebo) in clinical trials. 
- Main drug interactions: Carbonic anhydrase inhibitors and sodium bicarbonate may decrease excretion of memantine. Trimethoprim may enhance adverse/toxic effects of memantine, specifically the risk of myoclonus and/or delirium may be increased.

- Main side effects: Hypertension (4\%), dizziness (5-7\%), confusion $(6 \%)$, headache $(6 \%)$

- Special points: Periodic ophthalmic exams during use are recommended, as worsening of corneal conditions was observed during trials.

- Cost/cost effectiveness: About \$190 for $5 \mathrm{mg}$ or $10 \mathrm{mg}$ (60 tablets)

- Emerging therapies

O 5-HT2a Inverse Agonist

Pimavanserin - not yet available on the market, but doses of $40 \mathrm{mg}$ daily found to be effective in Phase III trial.

O MAO-B Inhibitor

Rasagiline

- Standard dosage: $0.5-1 \mathrm{mg} /$ day

- Contraindications: Concomitant use of cyclobenzaprine, dextromethorphan, methadone, propxyphene, St John's wort, tramadol, meperidine or MAO-Is (other than selective MAO-B inhibitors)

- Main drug interactions: Use of rasagiline with TCAs, SNRIs and SSRIs has been associated with rare occurrence of serotonin syndrome and should generally be avoided. Also avoid use in combination with ciprofloxacin and other CYP1A2 
inhibitors, which may increase rasagiline concentrations.

- Main side effects: Orthostatic hypotension (6-13\% as adjunct therapy), dyskinesia (18\% as adjunct therapy), headache (14\%), nausea (10-12\% as adjunct therapy)

- Special points: When added to existing levodopa therapy, a dose reduction of levodopa may be required to avoid exacerbation of dyskinesias. Patients should have regular and frequent skin examinations while on treatment, as there are reports of melanoma risk.

- Cost/cost effectiveness: About \$330 for $0.5 \mathrm{mg}$ or $1 \mathrm{mg}$ (30 tablets)

O Selective norepinephrine reuptake inhibitor

Atomoxetine

- Standard dosage: 25-100 mg/day

- Contraindications: Concomitant use of MAO-Is, narrow-angle glaucoma, current or past history of pheochromocytoma, severe cardiac or vascular disorders that would be expected to deteriorate with increases in blood pressure or heart rate.

- Main drug interactions: May enhance tachycardic effects of beta2agonists and sympathomimetics. MAO-Is may enhance the neurotoxic effects of atomoxetine and should definitely be avoided.

- Main side effects: Headache (2-19\%), insomnia (2-15\%), somnolence (4-11\%), xerostomia (21\%), nausea (7-21\%), abdominal pain (7-18\%), decreased appetite (11-16\%), vomiting 3-11\%). 
- Special points: New or worsening symptoms of hostility or aggressive behaviors have been associated with atomoxetine, particularly with initation of therapy

- Cost/cost effectiveness: About \$150 for $10 \mathrm{mg}$ or $25 \mathrm{mg}$ (30 tablets), or $\$ 170$ for $40 \mathrm{mg}$ (30 tablets)

\section{Acknowledgments}

Jennifer G. Goldman has received grant/research support from Teva, NIH K23NS060949, and the Parkinson's Disease Foundation; has served as a consultant for Pfizer; and has received honoraria from the Movement Disorder Society, the American Academy of Neurology, Teva, Medscape, and the Michael J. Fox Foundation.

\section{References}

[1]. Barone P, Antonini A, Colosimo C, Marconi R, Morgante L, Avarello TP, et al. The PRIAMO study: A multicenter assessment of nonmotor symptoms and their impact on quality of life in Parkinson's disease. Mov Disord. Aug 15.2009 24:1641-9. [PubMed: 19514014]

[2]. Weintraub D, Burn DJ. Parkinson's disease: the quintessential neuropsychiatric disorder. Mov Disord. May.2011 26:1022-31. [PubMed: 21626547]

[3]. Aarsland D, Larsen JP, Tandberg E, Laake K. Predictors of nursing home placement in Parkinson's disease: a population-based, prospective study. J Am Geriatr Soc. Aug.2000 48:93842. [PubMed: 10968298]

[4]. Goetz CG, Stebbins GT. Risk factors for nursing home placement in advanced Parkinson's disease. Neurology. Nov 43.1993 :2227-9. [PubMed: 8232934]

[5]. Goetz CG, Stebbins GT. Mortality and hallucinations in nursing home patients with advanced Parkinson's disease. Neurology. Apr.1995 45:669-71. [PubMed: 7723953]

[6]. Fenelon G, Alves G. Epidemiology of psychosis in Parkinson's disease. J Neurol Sci. Feb 15.2010 289:12-7. [PubMed: 19740486]

[7]. Ravina B, Marder K, Fernandez HH, Friedman JH, McDonald W, Murphy D, et al. Diagnostic criteria for psychosis in Parkinson's disease: report of an NINDS, NIMH work group. Mov Disord. Jun 15.2007 22:1061-8. [PubMed: 17266092]

[8]. Fenelon G, Soulas T, Zenasni F, de Langavant LC. The changing face of Parkinson's diseaseassociated psychosis: a cross-sectional study based on the new NINDS-NIMH criteria. Mov Disord. Apr 30.2010 25:755-9. [PubMed: 20437540]

[9]. Fenelon G, Mahieux F, Huon R, Ziegler M. Hallucinations in Parkinson's disease: prevalence, phenomenology and risk factors. Brain. Apr; 2000 123(Pt 4):733-45. [PubMed: 10734005]

[10]. Sanchez-Ramos JR, Ortoll R, Paulson GW. Visual hallucinations associated with Parkinson disease. Arch Neurol. Dec.1996 53:1265-8. [PubMed: 8970453]

[11]. Diederich NJ, Fenelon G, Stebbins G, Goetz CG. Hallucinations in Parkinson disease. Nat Rev Neurol. Jun.2009 5:331-42. [PubMed: 19498436]

[12]. Fenelon G, Mahieux F. [Hallucinations and dementia. Prevalence, clinical presentation and pathophysiology]. Rev Neurol (Paris). Apr.2004 160:S31-43. [PubMed: 15118551]

[13]. Goetz CG, Stebbins GT, Ouyang B. Visual plus nonvisual hallucinations in Parkinson's disease: Development and evolution over 10 years. Mov Disord. Oct.2011 26:2196-200. [PubMed: 21755536]

[14]. Aarsland D, Marsh L, Schrag A. Neuropsychiatric Symptoms in Parkinson's Disease. Movement Disorders. 2009; 24:2175-86. [PubMed: 19768724] 
[15]. Pagonabarraga J, Llebaria G, Garcia-Sanchez C, Pascual-Sedano B, Gironell A, Kulisevsky J. A prospective study of delusional misidentification syndromes in Parkinson's disease with dementia. Mov Disord. Feb 15.2008 23:443-8. [PubMed: 18076112]

[16]. Goldman JG. New thoughts on thought disorders in Parkinson's disease: review of current research strategies and challenges. Parkinsons Dis. 2011; 2011:675630. [PubMed: 21403865]

[17]. Moskovitz C, Moses H 3rd, Klawans HL. Levodopa-induced psychosis: a kindling phenomenon. Am J Psychiatry. Jun.1978 135:669-75. [PubMed: 655276]

[18]. Huot P, Johnston TH, Darr T, Hazrati LN, Visanji NP, Pires D, et al. Increased 5-HT2A receptors in the temporal cortex of parkinsonian patients with visual hallucinations. Mov Disord. Jul 30.2010 25:1399-408. [PubMed: 20629135]

[19]. Olanow CW, Watts RL, Koller WC. An algorithm (decision tree) for the management of Parkinson's disease (2001): treatment guidelines. Neurology. Jun.2001 56:S1-S88. [PubMed: 11402154]

[20]. Aarsland D, Perry R, Larsen JP, McKeith IG, O’Brien JT, Perry EK, et al. Neuroleptic sensitivity in Parkinson's disease and parkinsonian dementias. J Clin Psychiatry. May.2005 66:633-7. [PubMed: 15889951]

[21]. Miyasaki JM, Shannon K, Voon V, Ravina B, Kleiner-Fisman G, Anderson K, et al. Practice Parameter: evaluation and treatment of depression, psychosis, and dementia in Parkinson disease (an evidence-based review): report of the Quality Standards Subcommittee of the American Academy of Neurology. Neurology. Apr 11.2006 66:996-1002. [PubMed: 16606910]

[22]. Seppi K, Weintraub D, Coelho M, Perez-Lloret S, Fox SH, Katzenschlager R, et al. The Movement Disorder Society Evidence-Based Medicine Review Update: Treatments for the nonmotor symptoms of Parkinson's disease. Mov Disord. Oct; 2011 26(Suppl 3):S42-80. [PubMed: 22021174] • Evidence-based review of PD psychosis treatments, follow-up report from the MDS.

[23]. Factor SA, Friedman JH, Lannon MC, Oakes D, Bourgeois K. Clozapine for the treatment of drug-induced psychosis in Parkinson's disease: results of the 12 week open label extension in the PSYCLOPS trial. Mov Disord. Jan.2001 16:135-9. [PubMed: 11215574]

[24]. Merims D, Balas M, Peretz C, Shabtai H, Giladi N. Rater-blinded, Prospective Comparison: Quetiapine Versus Clozapine for Parkinson's Disease Psychosis. Clin Neuropharmacol. 2006; 26:331-7. [PubMed: 17095896]

[25]. Morgante L, Epifanio A, Spina E, Di Rosa AE, Zappia M, Basile G, et al. Quetiapine versus clozapine: a preliminary report of comparative effects on dopaminergic psychosis in patients with Parkinson's disease. Neurol Sci. Sep; 2002 23(Suppl 2):S89-90. [PubMed: 12548358]

[26]. Fernandez HH, Okun MS, Rodriguez RL, Malaty IA, Romrell J, Sun A, et al. Quetiapine improves visual hallucinations in Parkinson disease but not through normalization of sleep architecture: results from a double-blind clinical-polysomnography study. Int J Neurosci. 2009; 119:2196-205. [PubMed: 19916848]

[27]. Ondo WG, Tintner R, Voung KD, Lai D, Ringholz G. Double-blind, placebo-controlled, unforced titration parallel trial of quetiapine for dopaminergic-induced hallucinations in Parkinson's disease. Mov Disord. Aug.2005 20:958-63. [PubMed: 15800937]

[28]. Rabey JM, Prokhorov T, Miniovitz A, Dobronevsky E, Klein C. Effect of quetiapine in psychotic Parkinson's disease patients: a double-blind labeled study of 3 months' duration. Mov Disord. Feb 15.2007 22:313-8. [PubMed: 17034006]

[29]. Shotbolt P, Samuel M, Fox C, David AS. A randomized controlled trial of quetiapine for psychosis in Parkinson's disease. Neuropsychiatr Dis Treat. 2009; 5:327-32. [PubMed: 19557142]

[30]. Weintraub D, Chen P, Ignacio RV, Mamikonyan E, Kales HC. Patterns and trends in antipsychotic prescribing for Parkinson disease psychosis. Arch Neurol. Jul.2011 68:899-904. [PubMed: 21747029]

[31]. Hubbard D, Hacksell U, McFarland K. Behavioral effects of clozapine, pimavanserin, and quetiapine in rodent models of Parkinson's disease and Parkinson's disease psychosis: evaluation of therapeutic ratios. Behav Pharmacol. Aug 21.2013 
[32]. Friedman JH, Ravina B, Mills R, Burn D, Williams H, Revell S, et al. A multicenter, placebo controlled, double blind trial to examine the safety and efficacy of pimavanserin in the treatment of psychosis in Parkinson's disease. Neurology. 2010; 74:A299.

[33]. Cummings J, Isaacson S, Mills R. Antipsychotic efficacy and motor tolerability in a phase III placebo controlled study of pimavanserin in patients with Parkinson's disease psychosis (ACP 103-020). Neurology (abstract). 2013

[34]. Friedman JH. Pimavanserin for the treatment of Parkinson's disease psychosis. Expert Opin Pharmacother. Oct.2013 14:1969-75. [PubMed: 24016069]

[35]. Fabbrini G, Barbanti P, Aurilia C, Pauletti C, Lenzi GL, Meco G. Donepezil in the treatment of hallucinations and delusions in Parkinson's disease. Neurol Sci. Apr.2002 23:41-3. [PubMed: 12111620]

[36]. Kurita A, Ochiai Y, Kono Y, Suzuki M, Inoue K. The beneficial effect of donepezil on visual hallucinations in three patients with Parkinson's disease. J Geriatr Psychiatry Neurol. Sep.2003 16:184-8. [PubMed: 12967063]

[37]. Bergman J, Lerner V. Successful use of donepezil for the treatment of psychotic symptoms in patients with Parkinson's disease. Clin Neuropharmacol. Mar-Apr;2002 25:107-10. [PubMed: 11981238]

[38]. Reading PJ, Luce AK, McKeith IG. Rivastigmine in the treatment of parkinsonian psychosis and cognitive impairment: preliminary findings from an open trial. Mov Disord. Nov.2001 16:11714. [PubMed: 11748755]

[39]. Rovers JM, Dautzenberg PL, ter Bruggen JP. [Rivastigmine as adjunctive therapy in the therapeutic dilemma for the treatment of hallucinations due to Parkinson disease]. Tijdschr Gerontol Geriatr. Jul.2006 37:117-20. [PubMed: 16886519]

[40]. Burn D, Emre M, McKeith I, De Deyn PP, Aarsland D, Hsu C, et al. Effects of rivastigmine in patients with and without visual hallucinations in dementia associated with Parkinson's disease. Mov Disord. Nov.2006 21:1899-907. [PubMed: 16960863]

[41]. Bullock R, Cameron A. Rivastigmine for the treatment of dementia and visual hallucinations associated with Parkinson's disease: a case series. Curr Med Res Opin. 2002; 18:258-64. [PubMed: 12240787]

[42]. Ravina B, Putt M, Siderowf A, Farrar JT, Gillespie M, Crawley A, et al. Donepezil for dementia in Parkinson's disease: a randomised, double blind, placebo controlled, crossover study. J Neurol Neurosurg Psychiatry. Jul.2005 76:934-9. [PubMed: 15965198]

[43]. Aarsland D, Laake K, Larsen JP, Janvin C. Donepezil for cognitive impairment in Parkinson's disease: a randomised controlled study. J Neurol Neurosurg Psychiatry. Jun.2002 72:708-12. [PubMed: 12023410]

[44]. Emre M, Aarsland D, Albanese A, Byrne EJ, Deuschl G, De Deyn PP, et al. Rivastigmine for dementia associated with Parkinson's disease. N Engl J Med. Dec 9.2004 351:2509-18. [PubMed: 15590953]

[45]. Breier A, Sutton VK, Feldman PD, Kadam DL, Ferchland I, Wright P, Friedman JH. Olanzapine in the Treatment of Dopamimetic-Induced Psychosis in Patients with Parkinson's Disease. Biol Psychiatry. 2002; 52:438-45. [PubMed: 12242060]

[46]. Goetz CG, Blasucci L, Leurgans S, Pappert EJ. Olanzapine and clozapine Comparative effects on motor function in hallucinating PD patients. Neurology. 2000; 55:789-94. [PubMed: 10993997]

[47]. Ondo WG, Levy JK, Vuong KD, Hunter C, Jankovic J. Olanzapine treatment for dopaminergicinduced hallucinations. Mov Disord. Sep.2002 17:1031-5. [PubMed: 12360554]

[48]. Fernandez HH, Trieschmann ME, Friedman JH. Aripiprazole for drug-induced psychosis in Parkinson disease: preliminary experience. Clin Neuropharmacol. Jan-Feb;2004 27:4-5. [PubMed: 15090928]

[49]. Friedman JH, Berman RM, Goetz CG, Factor SA, Ondo WG, Wojcieszek J, et al. Open-label flexible-dose pilot study to evaluate the safety and tolerability of aripiprazole in patients with psychosis associated with Parkinson's disease. Mov Disord. Dec.2006 21:2078-81. [PubMed: 17013906] 
[50]. Aarsland D, Andersen K, Larsen JP, Lolk A, Kragh-Sorensen P. Prevalence and characteristics of dementia in Parkinson disease: an 8-year prospective study. Arch Neurol. Mar.2003 60:387-92. [PubMed: 12633150]

[51]. Hely MA, Reid WG, Adena MA, Halliday GM, Morris JG. The Sydney multicenter study of Parkinson's disease: the inevitability of dementia at 20 years. Mov Disord. Apr 30.2008 23:83744. [PubMed: 18307261]

[52]. Emre M, Aarsland D, Brown R, Burn DJ, Duyckaerts C, Mizuno Y, et al. Clinical diagnostic criteria for dementia associated with Parkinson's disease. Mov Disord. Sep 15.2007 22:1689_ 707. quiz 837. [PubMed: 17542011]

[53]. Litvan I, Aarsland D, Adler CH, Goldman JG, Kulisevsky J, Mollenhauer B, et al. MDS task force on mild cognitive impairment in Parkinson's disease: Critical review of PD-MCI. Mov Disord. Aug 15.2011 26:1814-24. [PubMed: 21661055]

[54]. Aarsland D, Bronnick K, Larsen JP, Tysnes OB, Alves G. Cognitive impairment in incident, untreated Parkinson disease: the Norwegian ParkWest study. Neurology. Mar 31.2009 72:11216. [PubMed: 19020293]

[55]. Barnes J, Boubert L. Executive functions are impaired in patients with Parkinson's disease with visual hallucinations. J Neurol Neurosurg Psychiatry. Feb.2008 79:190-2. [PubMed: 18202206]

[56]. Llebaria G, Pagonabarraga J, Martinez-Corral M, Garcia-Sanchez C, Pascual-Sedano B, Gironell A, et al. Neuropsychological correlates of mild to severe hallucinations in Parkinson's disease. Mov Disord. Dec 15.2010 25:2785-91. [PubMed: 20960483]

[57]. Ramirez-Ruiz B, Junque C, Marti MJ, Valldeoriola F, Tolosa E. Neuropsychological deficits in Parkinson's disease patients with visual hallucinations. Mov Disord. Sep.2006 21:1483-7. [PubMed: 16705661]

[58]. Dubois B, Burn D, Goetz C, Aarsland D, Brown RG, Broe GA, et al. Diagnostic procedures for Parkinson's disease dementia: recommendations from the movement disorder society task force. Mov Disord. Dec.2007 22:2314-24. [PubMed: 18098298]

[59]. Litvan I, Goldman JG, Troster AI, Schmand BA, Weintraub D, Petersen RC, et al. Diagnostic criteria for mild cognitive impairment in Parkinson's disease: Movement Disorder Society Task Force guidelines. Mov Disord. Mar.2012 27:349-56. [PubMed: 22275317]

[60]. Aarsland D, Bronnick K, Williams-Gray C, Weintraub D, Marder K, Kulisevsky J, et al. Mild cognitive impairment in Parkinson disease: a multicenter pooled analysis. Neurology. Sep 21.2010 75:1062-9. [PubMed: 20855849]

[61]. Braak H, Ghebremedhin E, Rub U, Bratzke H, Del Tredici K. Stages in the development of Parkinson's disease-related pathology. Cell Tissue Res. Oct.2004 318:121-34. [PubMed: 15338272]

[62]. Halliday G, Hely M, Reid W, Morris J. The progression of pathology in longitudinally followed patients with Parkinson's disease. Acta Neuropathol. Apr.2008 115:409-15. [PubMed: 18231798]

[63]. McKeith IG, Dickson DW, Lowe J, Emre M, O’Brien JT, Feldman H, et al. Diagnosis and management of dementia with Lewy bodies: third report of the DLB Consortium. Neurology. Dec 27.2005 65:1863-72. [PubMed: 16237129]

[64]. Lippa CF, Duda JE, Grossman M, Hurtig HI, Aarsland D, Boeve BF, et al. DLB and PDD boundary issues: diagnosis, treatment, molecular pathology, and biomarkers. Neurology. Mar 13.2007 68:812-9. [PubMed: 17353469]

[65]. Rolinski M, Fox C, Maidment I, McShane R. Cholinesterase inhibitors for dementia with Lewy bodies, Parkinson's disease dementia and cognitive impairment in Parkinson's disease. Cochrane Database Syst Rev. 2012; 3:CD006504. [PubMed: 22419314]

[66]. Leroi I, Brandt J, Reich SG, Lyketsos CG, Grill S, Thompson R, et al. Randomized placebocontrolled trial of donepezil in cognitive impairment in Parkinson's disease. Int J Geriatr Psychiatry. Jan.2004 19:1-8. [PubMed: 14716693]

[67]. Dubois B, Tolosa E, Katzenschlager R, Emre M, Lees AJ, Schumann G, et al. Donepezil in Parkinson's disease dementia: a randomized, double-blind efficacy and safety study. Mov Disord. Sep 1.2012 27:1230-8. [PubMed: 22915447] ••Large, double-blind, placebo-controlled trial of donepezil in PD dementia. 
[68]. Edwards K, Royall D, Hershey L, Lichter D, Hake A, Farlow M, et al. Efficacy and safety of galantamine in patients with dementia with Lewy bodies: a 24-week open-label study. Dement Geriatr Cogn Disord. 2007; 23:401-5. [PubMed: 17409748]

[69]. Litvinenko IV, Odinak MM, Mogil'naya VI, Emelin AY. Efficacy and safety of galantamine (reminyl) for dementia in patients with Parkinson's disease (an open controlled trial). Neurosci Behav Physiol. Nov.2008 38:937-45. [PubMed: 18975103]

[70]. Aarsland D, Ballard C, Walker Z, Bostrom F, Alves G, Kossakowski K, et al. Memantine in patients with Parkinson's disease dementia or dementia with Lewy bodies: a double-blind, placebo-controlled, multicentre trial. Lancet Neurol. Jul.2009 8:613-8. [PubMed: 19520613]

[71]. Leroi I, Overshott R, Byrne EJ, Daniel E, Burns A. Randomized controlled trial of memantine in dementia associated with Parkinson's disease. Mov Disord. Jun 15.2009 24:1217-21. [PubMed: 19370737]

[72]. Emre M, Tsolaki M, Bonuccelli U, Destee A, Tolosa E, Kutzelnigg A, et al. Memantine for patients with Parkinson's disease dementia or dementia with Lewy bodies: a randomised, doubleblind, placebo-controlled trial. Lancet Neurol. Oct.2010 9:969-77. [PubMed: 20729148]

[73]. Linazasoro G, Lasa A, Van Blercom N. Efficacy and safety of donepezil in the treatment of executive dysfunction in Parkinson disease: a pilot study. Clin Neuropharmacol. Jul-Aug;2005 28:176-8. [PubMed: 16062096]

[74]. Grace J, Amick MM, Friedman JH. A double-blind comparison of galantamine hydrobromide ER and placebo in Parkinson disease. J Neurol Neurosurg Psychiatry. Jan.2009 80:18-23. [PubMed: 18931006]

[75]. Hanagasi HA, Gurvit H, Unsalan P, Horozoglu H, Tuncer N, Feyzioglu A, et al. The effects of rasagiline on cognitive deficits in Parkinson's disease patients without dementia: a randomized, double-blind, placebo-controlled, multicenter study. Mov Disord. Aug 15.2011 26:1851-8. [PubMed: 21500280]

[76]. Tzavara ET, Bymaster FP, Overshiner CD, Davis RJ, Perry KW, Wolff M, et al. Procholinergic and memory enhancing properties of the selective norepinephrine uptake inhibitor atomoxetine. Mol Psychiatry. Feb.2006 11:187-95. [PubMed: 16231039]

[77]. Zweig RM, Cardillo JE, Cohen M, Giere S, Hedreen JC. The locus ceruleus and dementia in Parkinson's disease. Neurology. May.1993 43:986-91. [PubMed: 8492957]

[78]. Marsh L, Biglan K, Gerstenhaber M, Williams JR. Atomoxetine for the treatment of executive dysfunction in Parkinson's disease: a pilot open-label study. Mov Disord. Jan 30.2009 24:27782. [PubMed: 19025777]

[79]. Weintraub D, Mavandadi S, Mamikonyan E, Siderowf AD, Duda JE, Hurtig HI, et al. Atomoxetine for depression and other neuropsychiatric symptoms in Parkinson disease. Neurology. Aug 3.2010 75:448-55. [PubMed: 20679638]

[80]. Hindle JV, Petrelli A, Clare L, Kalbe E. Nonpharmacological enhancement of cognitive function in Parkinson's disease: a systematic review. Mov Disord. Jul.2013 28:1034-49. [PubMed: 23426759] - Review of nonpharmacological treatments of cognitive dysfunction in PD.

[81]. Olazaran J, Reisberg B, Clare L, Cruz I, Pena-Casanova J, Del Ser T, et al. Nonpharmacological therapies in Alzheimer's disease: a systematic review of efficacy. Dement Geriatr Cogn Disord. 2010; 30:161-78. [PubMed: 20838046]

[82]. Sinforiani E, Banchieri L, Zucchella C, Pacchetti C, Sandrini G. Cognitive rehabilitation in Parkinson's disease. Arch Gerontol Geriatr Suppl. 2004:387-91. [PubMed: 15207437]

[83]. Mohlman J, Chazin D, Georgescu B. Feasibility and acceptance of a nonpharmacological cognitive remediation intervention for patients with Parkinson disease. J Geriatr Psychiatry Neurol. Jun.2011 24:91-7. [PubMed: 21546649]

[84]. Sammer G, Reuter I, Hullmann K, Kaps M, Vaitl D. Training of executive functions in Parkinson's disease. J Neurol Sci. Oct 25.2006 248:115-9. [PubMed: 16765378]

[85]. Disbrow EA, Russo KA, Higginson CI, Yund EW, Ventura MI, Zhang L, et al. Efficacy of tailored computer-based neurorehabilitation for improvement of movement initiation in Parkinson's disease. Brain Res. May 3.2012 1452:151-64. [PubMed: 22459048] 
[86]. Nombela C, Bustillo PJ, Castell PF, Sanchez L, Medina V, Herrero MT. Cognitive rehabilitation in Parkinson's disease: evidence from neuroimaging. Front Neurol. 2011; 2:82. [PubMed: 22203816]

[87]. Paris AP, Saleta HG, de la CruzCrespo Maraver M, Silvestre E, Freixa MG, Torrellas CP, et al. Blind randomized controlled study of the efficacy of cognitive training in Parkinson's disease. Mov Disord. Jun.2011 26:1251-8. [PubMed: 21442659]

[88]. Calleo J, Burrows C, Levin H, Marsh L, Lai E, York MK. Cognitive rehabilitation for executive dysfunction in Parkinson's disease: application and current directions. Parkinsons Dis. 2012; 2012:512892. [PubMed: 22135762]

[89]. Edwards JD, Hauser RA, O’Connor ML, Valdes EG, Zesiewicz TA, Uc EY. Randomized trial of cognitive speed of processing training in Parkinson disease. Neurology. Oct 8.2013 81:1284-90. [PubMed: 24014503]

[90]. Reuter I, Engelhardt M, Stecker K, Baas H. Therapeutic value of exercise training in Parkinson's disease. Med Sci Sports Exerc. Nov.1999 31:1544-9. [PubMed: 10589855]

[91]. Goodwin VA, Richards SH, Taylor RS, Taylor AH, Campbell JL. The effectiveness of exercise interventions for people with Parkinson's disease: a systematic review and meta-analysis. Mov Disord. Apr 15.2008 23:631-40. [PubMed: 18181210]

[92]. Thom JM, Clare L. Rationale for combined exercise and cognition-focused interventions to improve functional independence in people with dementia. Gerontology. 2011; 57:265-75. [PubMed: 20980736]

[93]. Quelhas R. Psychiatric care in Parkinson's disease. J Psychiatr Pract. Mar.2013 19:118-41. [PubMed: 23507813]

[94]. Ridgel AL, Kim CH, Fickes EJ, Muller MD, Alberts JL. Changes in executive function after acute bouts of passive cycling in Parkinson's disease. J Aging Phys Act. Apr.2011 19:87-98. [PubMed: 21558565]

[95]. Tanaka K, Quadros AC Jr. Santos RF, Stella F, Gobbi LT, Gobbi S. Benefits of physical exercise on executive functions in older people with Parkinson's disease. Brain Cogn. Mar.2009 69:43541. [PubMed: 19006643]

[96]. Cruise KE, Bucks RS, Loftus AM, Newton RU, Pegoraro R, Thomas MG. Exercise and Parkinson's: benefits for cognition and quality of life. Acta Neurol Scand. Jan.2011 123:13-9. [PubMed: 20199518]

[97]. Nardone R, Bergmann J, Christova M, Caleri F, Tezzon F, Ladurner G, et al. Effect of transcranial brain stimulation for the treatment of Alzheimer disease: a review. Int J Alzheimers Dis. 2012; 2012:687909. [PubMed: 22114748]

[98]. Bentwich J, Dobronevsky E, Aichenbaum S, Shorer R, Peretz R, Khaigrekht M, et al. Beneficial effect of repetitive transcranial magnetic stimulation combined with cognitive training for the treatment of Alzheimer's disease: a proof of concept study. J Neural Transm. Mar.2011 118:46371. [PubMed: 21246222]

[99]. Boggio PS, Ferrucci R, Rigonatti SP, Covre P, Nitsche M, Pascual-Leone A, et al. Effects of transcranial direct current stimulation on working memory in patients with Parkinson's disease. J Neurol Sci. Nov 1.2006 249:31-8. [PubMed: 16843494]

[100]. Sedlackova S, Rektorova I, Srovnalova H, Rektor I. Effect of high frequency repetitive transcranial magnetic stimulation on reaction time, clinical features and cognitive functions in patients with Parkinson's disease. J Neural Transm. Sep.2009 116:1093-101. [PubMed: 19588221] 


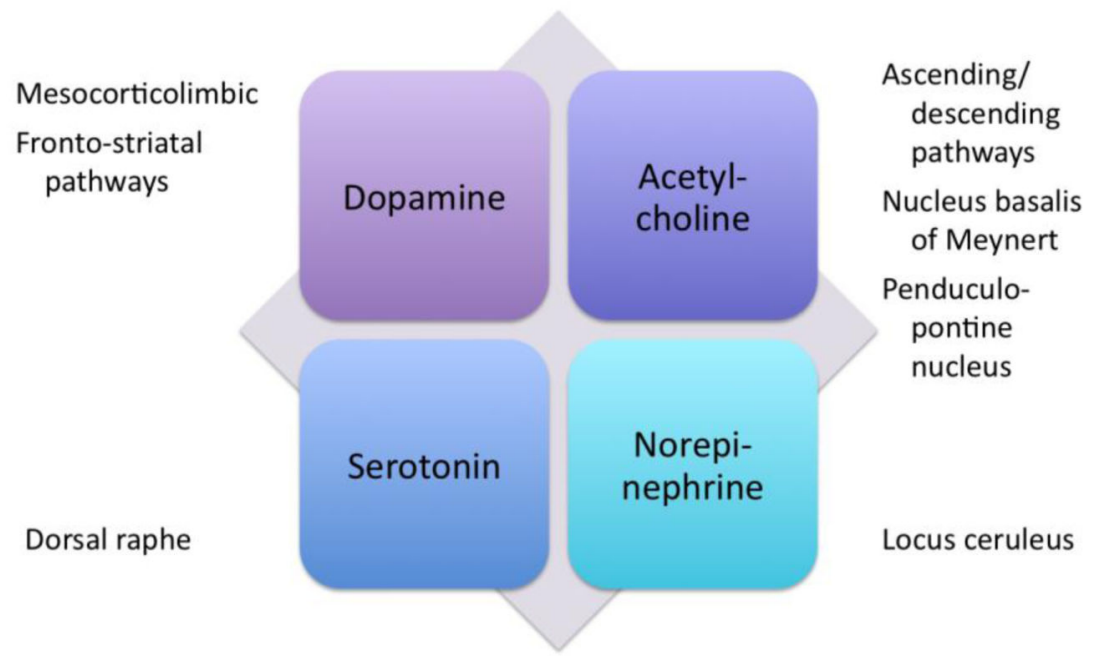

Figure 1. Neurochemical substrates in psychosis and cognitive impairment in PD 
Table 1

Phenomenology and examples of PD psychosis and cognitive deficits

\begin{tabular}{|c|c|}
\hline \multicolumn{2}{|l|}{ Psychosis } \\
\hline Illusions & $\begin{array}{l}\text { Misperceiving or misinterpreting an object really } \\
\text { present } \\
\text { Mistaking a lamp-post for a person or a chair for a } \\
\text { dog }\end{array}$ \\
\hline Presence hallucinations & Feeling that someone or a shadow is close by \\
\hline Passage hallucinations & Experiencing fleeting images in the visual periphery \\
\hline Simple hallucinations & Seeing flashes of light, colors, lines, patterns \\
\hline Complex hallucinations & $\begin{array}{l}\text { Seeing formed images of people (little children at } \\
\text { play; distorted figures; deceased relatives), animals } \\
\text { (small furry animals running around), objects } \\
\text { Hearing music and voices }\end{array}$ \\
\hline Multi-modal hallucinations & $\begin{array}{l}\text { Having hallucinations in more than modality: visual, } \\
\text { auditory, tactile, and/or olfactory; most common } \\
\text { visual plus auditory modalities }\end{array}$ \\
\hline Delusions & $\begin{array}{l}\text { Having false beliefs; for example, that someone is } \\
\text { unfaithful or may harm them (infidelity, paranoia) }\end{array}$ \\
\hline Misidentification syndromes & $\begin{array}{l}\text { Capgras syndrome: Thinking that one's spouse is an } \\
\text { imposter } \\
\text { Fregoli syndrome: Thinking that familiar people are } \\
\text { disguised as strangers }\end{array}$ \\
\hline \multicolumn{2}{|l|}{ Cognitive impairment } \\
\hline $\begin{array}{l}\text { Attention and working } \\
\text { memory }\end{array}$ & $\begin{array}{l}\text { Trouble concentrating or focusing } \\
\text { Difficulty keeping track of information in one's mind }\end{array}$ \\
\hline Executive function & $\begin{array}{l}\text { Problems with planning, organizing, or initiating } \\
\text { activities } \\
\text { Difficulty with "multi-tasking" } \\
\text { Trouble stopping and starting tasks }\end{array}$ \\
\hline Memory & $\begin{array}{l}\text { Problems with learning new tasks or recalling facts } \\
\text { or events } \\
\text { Difficulty performing learned tasks like riding a } \\
\text { bicycle planning, organizing, or initiating activities }\end{array}$ \\
\hline Language & $\begin{array}{l}\text { Difficulty finding words or naming } \\
\text { Reduced fluency of speech }\end{array}$ \\
\hline Visuospatial function & $\begin{array}{l}\text { Impaired sense of direction } \\
\text { Getting lost or "turned around" } \\
\text { Difficulty drawing objects }\end{array}$ \\
\hline
\end{tabular}

